\title{
Hydrodynamic considerations on optimal design of a three-phase airlift bioreactor with high solids loading
}

\author{
Jaroslav Klein, António A Vicente and José A Teixeira* \\ Centro de Engenharia Biológica-IBQF, Universidade do Minho, 4710-057 Braga, Portugal
}

\begin{abstract}
The hydrodynamic study of a three-phase airlift (TPAL) bioreactor with an enlarged gas-liquid dual separator was carried out. Different lengths and diameters of the draft tube were tested to show how the design of the separator zone affects the hydrodynamic performance of the TPAL reactor. Ca-alginate beads with entrapped yeast biomass at different loadings $(0,7,14$ and $21 \% \mathrm{v} / \mathrm{v})$ were used in order to mimic the solid phase of conventional high cell density systems, such as those with cells immobilized on carriers or flocculating cells. Important information on multiphase flow and distribution of gas and solid phases in the internal-loop airlift reactor (ALR) with high solids loading was obtained, which can be used for suggesting optimal hydrodynamic conditions in a TPAL bioreactor with high solids loading. It is finally suggested that the ALR with a dual separator and a downcomer to riser cross-sectional area ratio $\left(A_{\mathrm{D}} / A_{\mathrm{R}}\right)$ ranging from 1.2 to 2.0 can be successfully applied to batch/continuous high cell density systems, where the uniform distribution of solid phase, its efficient separation of particles from the liquid phase, and an improved residence time of air bubbles inside the reactor are desirable.
\end{abstract}

(C) 2003 Society of Chemical Industry

Keywords: airlift bioreactor; hydrodynamics; three-phase flow; solids distribution; dual gas-liquid separator

\section{NOTATION}

A

$\mathrm{D}$

$\mathrm{H}$

$\mathrm{t}$

U

V

$\begin{array}{ll}\varepsilon & \text { Holdup } \\ \rho & \text { Density }\left(\mathrm{kg} \mathrm{m}^{-3}\right) \\ \phi_{\text {S,tot }} & \text { Solids loading }\end{array}$

b

c

crit

C

$\mathrm{D}$

DT

G

$\mathrm{L}$

$\mathrm{R}$

$\mathrm{S}$

SEP

$\mathrm{T}$

TOT

Height (m)

Time (s)

Bubble

Critical

Downcomer

Draft tube

Gas phase

Liquid phase

Riser

Solid phase

Separator

Top

Total
Cross-sectional area $\left(\mathrm{m}^{2}\right)$

Column diameter $(\mathrm{m})$

Superficial velocity $\left(\mathrm{ms}^{-1}\right)$

Linear velocity $\left(\mathrm{ms}^{-1}\right)$

Averaged at geometrical center of column

Circulation/column

\section{INTRODUCTION}

In recent years, there has been growing interest in bioreactors, which utilize immobilized enzymes and cells in order to improve bioprocess productivity. ${ }^{1}$ The immobilized system usually represents a three-phase dispersion, where an intimate contact of gas, liquid and solid phases should be ensured. Three-phase airlift (TPAL) bioreactors provide such a suitable environment and the advantageous combination of controlled mixing and low shear rate and the efficient suspension of solids makes the airlift system attractive for bioprocesses where microorganisms are immobilized on/in solid carriers (eg biofilm particles) ${ }^{2}$ or flocculate (eg flocculent Saccharomyces cerevisiae). ${ }^{3}$ In these high cell density systems, solids loadings as high as $30-40 \%$ of the total reactor volume may be attained, which are necessary to achieve a high conversion in a continuous bioprocess. This amount of particles can be completely suspended in a TPAL with a lower energy requirement compared with bubble columns. ${ }^{4}$ This advantage of the airlift reactor (ALR) results from the existence of a liquid circulation loop inside the reactor originating from the density difference established between the riser and downcomer sections.

The liquid circulation velocity is an essential parameter in the design of the TPAL reactor because

* Correspondence to: José A Teixeira, Centro de Engenharia Biológica-IBQF, Universidade do Minho, 4710-057 Braga, Portugal

E-mail: jateixeira@deb.uminho.pt

Contract/grant sponsor: European Community; contract/grant number: HPMF-CT-2002-01643

(Received 1 August 2002; revised version received 31 March 2003; accepted 20 May 2003) 
of its crucial effect on various subprocesses - mixing, extent of bubble recirculation, efficiency of solids suspension and distribution of gas and solids holdups. ${ }^{5}$ Thus, the knowledge of the liquid circulation rate is of particular importance. In practice, the magnitude of the driving force for liquid circulation $\left(\varepsilon_{\mathrm{GR}}-\varepsilon_{\mathrm{GD}}\right)$ is often affected by the downcomer gas holdup $\varepsilon_{\mathrm{GD}}$, ie by the intensity of bubbles penetration into the downcomer section. In coalescing liquids, the bubble separation from the liquid phase can be basically manipulated by two geometrical parameters - downcomer to riser cross-sectional area ratio $\left(A_{\mathrm{D}} / A_{\mathrm{R}}\right)$ and geometry of the gas-liquid separator zone.

The important role of the area ratio $A_{\mathrm{D}} / A_{\mathrm{R}}$ in the hydrodynamic behavior of the airlift reactor was shown by several authors, eg Refs $6-10$. The area ratio determines not only the intensity of gas recirculation but also the pressure loss in the circulation loop. Weiland $^{6}$ investigated the effect of the draft tube to column diameter ratio $\left(D_{\mathrm{D}} / D_{\mathrm{C}}\right)$, which ranged from 0.59 up to 0.88 (corresponding to values of $A_{\mathrm{D}} / A_{\mathrm{R}}$ from 1.96 to 0.26 ), on all important operating parameters in an internal-loop ALR. It was pointed out that there is no single diameter ratio ensuring the most favorable conditions for all the operating parameters. The author determined an optimal value of the diameter ratio between 0.8 and 0.9 for cultures with high oxygen demand and a lower value (around 0.6 ) for biosystems with solid particles in order to avoid their sedimentation. Miyahara et $a l^{7}$ confirmed these observations, finding the maximal value of the liquid velocity for the ratio $D_{\mathrm{D}} / D_{\mathrm{C}}$ equal to 0.6. Gavrilescu and Tudose ${ }^{9}$ and Al-Masry and Abaseed ${ }^{10}$ observed the same impact of the area ratio $A_{\mathrm{D}} / A_{\mathrm{R}}$ in the range of 0.04 to 1 (corresponding to the diameter ratio values approx from 0.98 to 0.71 ) on the liquid circulation in an external-loop ALR.

The design of the gas-liquid separator zone can have also a substantial impact on the performance of the ALR and the transport phenomena taking place there, as reported in several works. ${ }^{1-13}$ Basically, the head separator zone is usually designed with the purpose of controlling the extent of bubble penetration into the downcomer. This is usually achieved by changing the size of the reactor head zone (ie diameter, height). Most of the studies found in the literature dealing with internal-loop ALR used a reactor configuration where the diameter of the head separator zone equals that of the outer column $\left(D_{\mathrm{SEP}}=D_{\mathrm{C}}\right)$. Considerably fewer works exist on the impact of an enlarged separator zone on the hydrodynamics of two-phase (gas-liquid) ALR. ${ }^{11,12,14-16}$ Moreover, the enlarged head zone can act as an efficient sedimentation zone, which can be exploited in continuous three-phase biosystems, where the efficient separation of the solid particles from the liquid is of particular importance. Despite this fact, only a few recent studies have covered the research of three-phase flow in ALR with such an enlarged head zone. ${ }^{8,17}$
In the present study, experiments were performed to determine the liquid circulation velocity, and the gas and solids holdups in individual parts of an ARL containing low-density solid particles. The work was focused on the investigation of the effect of the enlarged separator zone and the riser to downcomer cross-sectional area ratio on the reactor hydrodynamics in the presence of a threephase (gas-liquid-solid) system. Different lengths and diameters of the draft tube were tested to show how the design of the dual separator (acting simultaneously as a degassing and a sedimentation zone) affected the hydrodynamic performance of the internal-loop ALR.

\section{MATERIALS AND METHODS}

\subsection{The reactor set-up}

A $50 \mathrm{dm}^{3}$ internal-loop ALR with an enlarged degassing zone was used for hydrodynamic measurements with three inner tubes of different diameters and lengths labelled as 1DT, 2DT and 3DT (see Fig 1). The basic dimensions of the reactor and variations of the configurations are listed in Table 1.

The head section has the shape of a reversed cut cone with a cylindrical overhead. The conical section forms a $51^{\circ}$ angle with the main body of the reactor. The reactor was basically designed to be used in a continuous operation; a drainage tube for liquid overflow protected by a half of larger tube forming a local settler were positioned at the reactor wall to keep the volume level constant at $50 \mathrm{dm}^{3}$.

In view of the separator design, internal-loop airlift reactors are conventionally divided into ALR without a separator $\left(D_{\mathrm{SEP}}=D_{\mathrm{C}}\right)$ and ALR with a separator $\left(D_{\mathrm{SEP}}>D_{\mathrm{C}}\right) .{ }^{5}$ In the ALR reactor with an enlarged head zone, different separator configurations can be easily achieved only by adjusting the length of the draft tube. Two basic constructions of the ALR were considered:

A. The top of the draft tube is located exactly at/above the opening of the enlarged zone; in this case the separator consists only of the enlarged section (see Fig 1(A)), which acts as a bubble separation zone as well as a particle settler. Such a reactor configuration represents the airlift reactor with a simple enlarged separator (configuration label 1DT).

B. The top of the draft tube is located below the opening of the enlarged zone inside the downcomer column; in this case the separator consists of two parts (see Fig 1(B)) - a lower narrow part acting as bubble separation zone with high mixing intensity and the upper enlarged zone acting as the particle settler. In fact, such a reactor configuration should be included in the group of ALR with a separator according to terminology conventionally used in airlift reactor engineering. However, in view of the bubble separation efficiency, this is the ALR without separator. For all that, this configuration 


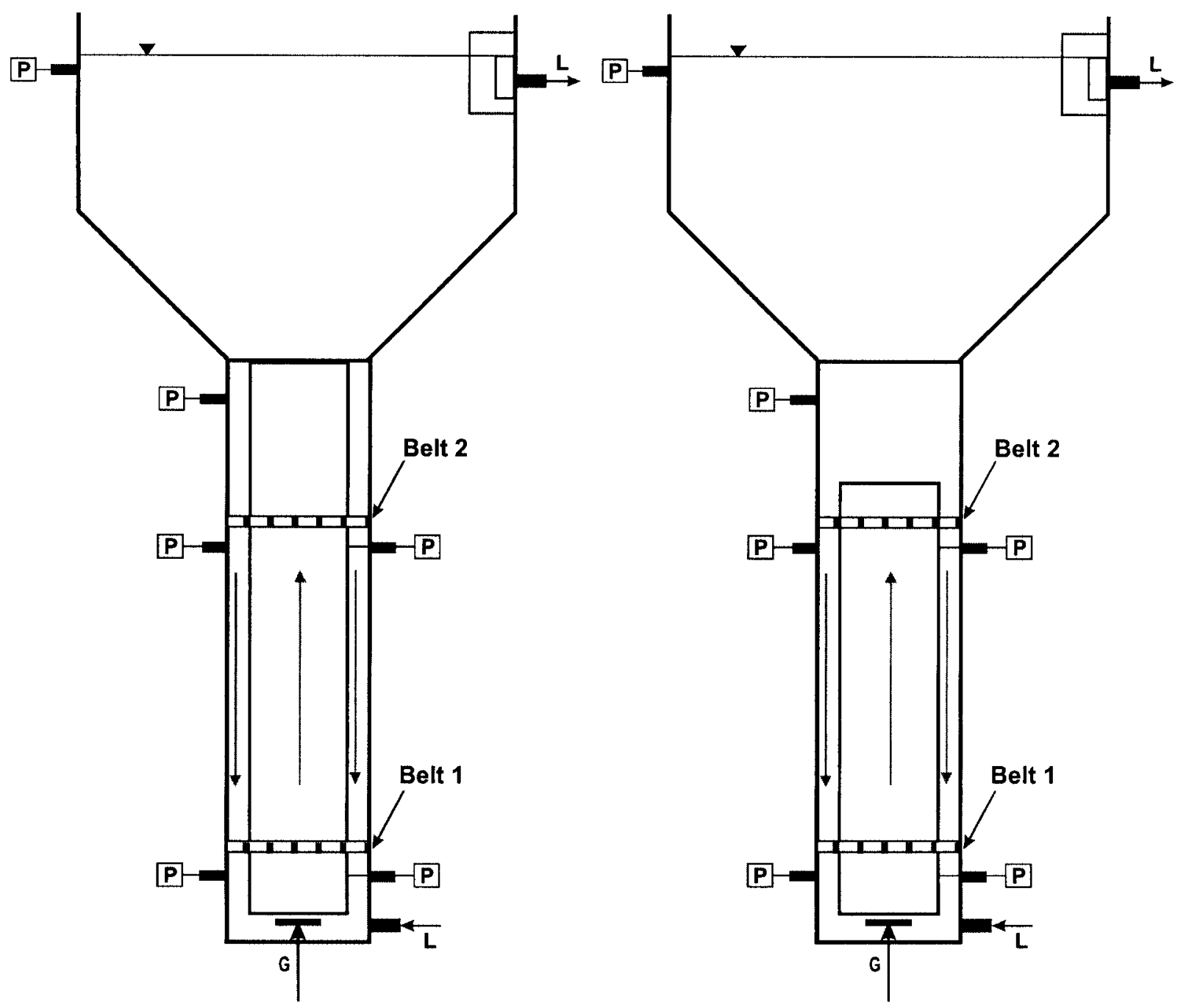

Figure 1. Schematic of the airlift reactor. Belts 1 and 2 indicate the position of the measuring coils for the velocity measurement by the magnetic tracer method. P-Manometer taping, L- liquid phase, G-gas phase. A: Configuration 1DT - ALR with simple separator; B: Configurations 2DT and 3DT - ALR with dual separator.

Table 1. Basic characteristics of airlift used in this study

\begin{tabular}{lcccccccc}
\hline Label & $D_{\mathrm{C}}(\mathrm{m})$ & $H_{\mathrm{C}}(\mathrm{m})$ & $D_{\mathrm{R}}(\mathrm{m})$ & $A_{\mathrm{D}} / A_{\mathrm{R}}$ & $H_{\mathrm{DT}}(\mathrm{m})$ & $H_{\mathrm{T}}(\mathrm{m})$ & $D_{\text {SEP }}(\mathrm{m})$ & $H_{\text {SEP }}(\mathrm{m})$ \\
\hline 1DT & $0.142 / 0.150$ & 2.0 & $0.092 / 0.10$ & 1.20 & 1.4 & 0.292 & 0.442 & 0.350 \\
2DT & $0.142 / 0.150$ & 2.0 & $0.092 / 0.10$ & 1.20 & 1.2 & 0.492 & 0.442 & 0.350 \\
3DT & $0.142 / 0.150$ & 2.0 & $0.062 / 0.07$ & 3.97 & 1.2 & 0.492 & 0.442 & 0.350 \\
\hline
\end{tabular}

$D_{\mathrm{C}}-$ column diameter, $H_{\mathrm{C}}$ - height of column, $D_{\mathrm{R}}$ - riser draft tube diameter, $A_{\mathrm{R}}$ - riser cross-sectional area, $A_{\mathrm{D}}-$ downcomer cross-sectional area, $H_{\mathrm{DT}}$ - height of the draft tube, $H_{\mathrm{T}}$ - height of liquid level above the top of draft tube, $D_{\mathrm{SEP}}-$ diameter of separator zone, $H_{\mathrm{SEP}}-$ height of separator zone.

of the head zone was entitled 'dual' separator (configuration labels 2DT and 3DT).

In all the experiments, water and air were used as the liquid and gas phases, respectively. The experiments were carried out at the temperature of $19 \pm 1{ }^{\circ} \mathrm{C}$ and atmospheric pressure. Air injection was made $0.061 \mathrm{~m}$ below the bottom of the draft tube by means of a perforated plate with a diameter of $0.03 \mathrm{~m}$, with 30 holes of $1 \mathrm{~mm}$ each. The air flow rate was controlled by means of rotameters and ranged from 2 up to $70 \mathrm{dm}^{3} \min ^{-1}$ (referred to pressure of $1 \mathrm{~atm}$ and temperature $20^{\circ} \mathrm{C}$ ), covering most flow rates applied in fermentation processes. In the present work, the air flow rate is given as the characteristic superficial velocity $\left(U_{\mathrm{Gc}}\right)$ referred to the column diameter, $D_{\mathrm{C}}$, in order to enable a correct comparison of ALR configurations with different cross-sectional area ratios, $A_{\mathrm{D}} / A_{\mathrm{R}}$. The parameter $U_{\mathrm{Gc}}$ was calculated for the conditions in the geometric center of the column.

\subsection{Solid phase}

Ca-alginate beads with immobilized cells were used as a solid phase, which mimic immobilizing carriers or yeast flocs. They have been prepared according to the 
procedure described by Vicente and Teixeira. ${ }^{8} \mathrm{Ca}$ alginate beads, prepared with an addition of killed compressed baker's yeasts, had a mean diameter of $2.15 \pm 0.13 \mathrm{~mm}$ and density of $1048 \pm 1 \mathrm{~kg} \mathrm{~m}^{-3}$. Three different solids loadings were used: 7,14 and $21 \%(\mathrm{v} / \mathrm{v})$ (see Table 1$)$.

\subsection{Liquid velocity}

A magnetic tracer method ${ }^{18}$ was used to determine the liquid velocity in the internal-loop ALR. The method makes use of a flow following technique in combination with a magnetic metal locator. A magnetic particle with a high magnetic permeability and a diameter of $1.1 \mathrm{~cm}$ was used as the flow follower. The particle density was practically equal to the liquid density, resulting in a very low terminal settling velocity (up to $1 \mathrm{~cm} \mathrm{~s}^{-1}$ ), when compared with the magnitude of liquid velocities achieved in the reactor. It utilizes a non-invasive technique without the need of a direct impact on the fluid inside the reactor (as is the case of an injection of electrolyte tracer). The method was developed to be used in fermentation systems with multiphase dispersion and had already been successfully tested in two-phase (air-water) systems. ${ }^{18}$ Moreover, the measuring technique allows the determination of the liquid velocity, the mean circulation velocity and the residence time of the flow follower in individual sections of the airlift reactor.

\subsection{Gas and solids holdup}

A method for simultaneous measurement of gas and solids holdups in gas-liquid-solid multiphase contactors suggested by Wenge et al ${ }^{19}$ was used.
This method was chosen because of its advantageous use in three-phase fermentation systems, where a direct outside contact with the fermentation broth should be avoided as much as possible because of contamination risks. The method makes use of measurements of hydrostatic pressure in the threephase dispersion followed by interruption of gas flow, complete gas disengagement, and a second measurement in the resulting two-phase (solid-liquid) dispersion. This measurement period has to be short enough to avoid significant sedimentation of the solid particles. Quick-response differential pressure transducers (Shaewitz Sensors, USA) were used for manometric measurements of pressure differences between two places in the riser, downcomer and separator of the ALR. The signal from the pressure sensors was sampled once per second and the data were collected by a PC through a standard data acquisition system. The positions of the measuring points were properly chosen in order to avoid the effect of liquid acceleration at the bottom and the top of the draft tube. ${ }^{12}$

\section{RESULTS AND DISCUSSION \\ 3.1 Gas holdup}

The effect of solids loading and air flow rate on gas holdups in the riser, downcomer and separator sections is shown in Fig 2. As can be seen in Fig 2, all partial gas holdups increased, as expected, in the whole range of applied air superficial velocity, $U_{\mathrm{Gc}}$. A constant increase of the gas holdups in the riser, $\varepsilon_{\mathrm{GR}}$, and in the separator, $\varepsilon_{\mathrm{GS}}$, was observed with the increase of

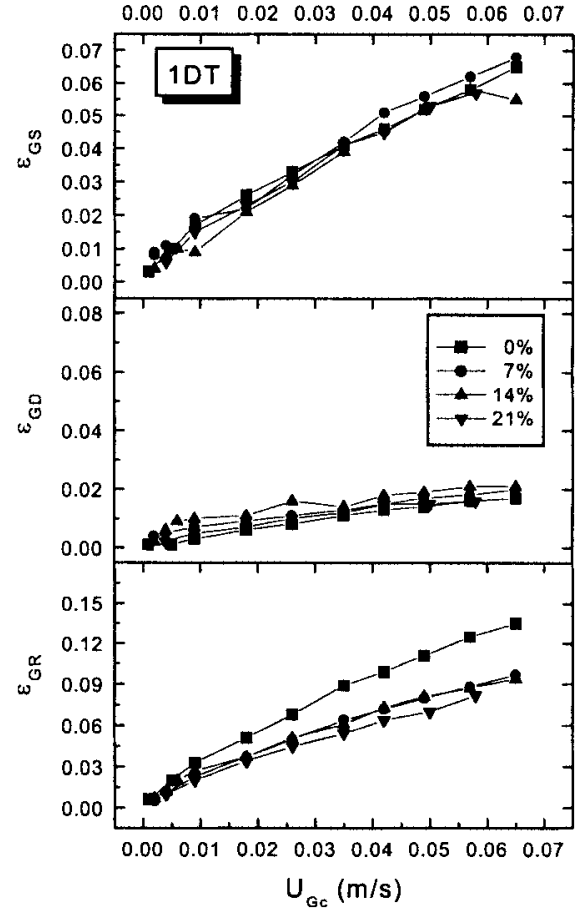

A.

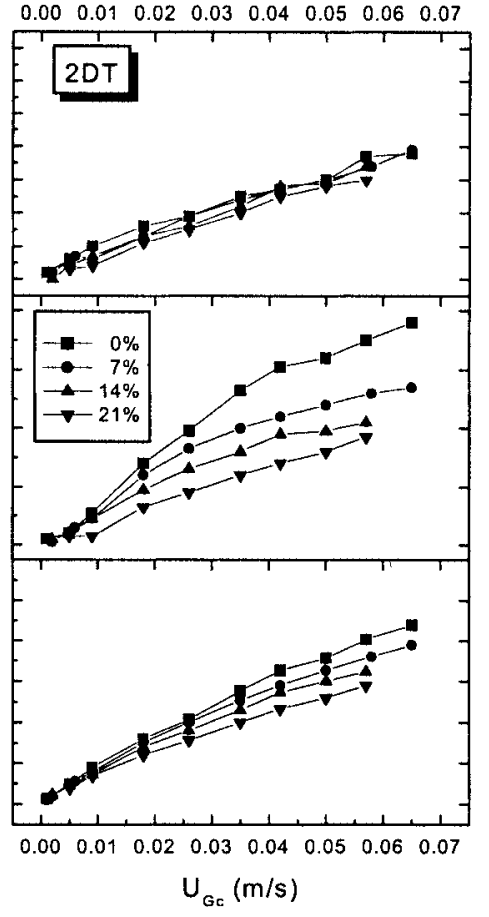

B.

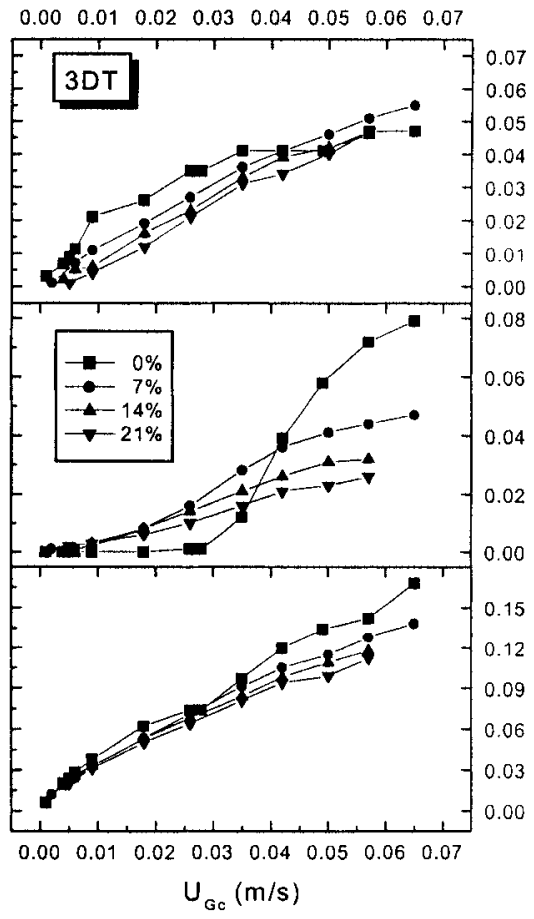

C.

Figure 2. Gas holdups in individual sections of the ALR versus air superficial velocity $U_{\mathrm{Gc}}$, for different solids loadings: $0 \%$, $7 \%$, $14 \%$ and $21 \%$ (v/v). A: ALR configuration 1DT, B: ALR configuration 2DT, C: ALR configuration 3DT (see also Table 1). 
the air flow rate for its lowest values. However, for high flow rates, the increase of the riser holdup was smaller because of the high values of the liquid velocity and because of the appearance of bubble coalescence (flow regime transition). A similar trend at high $U_{\mathrm{Gc}}$ could be observed on the curves of the gas holdup in the downcomer, $\varepsilon_{\mathrm{GD}}$. However, an initial plateau was displayed due to the fact that higher values of air flow rate were needed for entrainment of bubbles into the downcomer. It can be clearly seen that the energy demand for bubble penetration into the downcomer increased consecutively from the reactor configuration 1DT through 2DT to 3DT (see Fig 2 (A-C)).

In most cases, the solids loading had a negative effect on the gas holdup in all reactor sections. The gas holdup in the riser was observed to be reduced by increasing the solids loading for all reactor configurations. Similar trends have been noticed by Verlaan and Tramper ${ }^{20}$ and $\mathrm{Lu}$ et $a l^{21}$ in externalloop and internal-loop ALRs, respectively. The solids affect the building-up of gas holdup in the riser and downcomer in two ways: the presence of solids promotes bubble coalescence and an addition of solids reduces the flow area of the gas and liquid phases. Both result in a decrease of the residence time of bubbles, thus decreasing the gas holdup.

The downcomer gas holdup curves in the reactor configurations with the dual separator (2DT and 3DT) displayed the same trends with both the change of the solids loading and of the air flow rate, except for the air-water system in the reactor set 3DT (see Fig 2(C)). In this case, as opposed to the 2DT set, a fairly high air flow rate $\left(U_{\mathrm{Gc}}=0.03 \mathrm{~m} \mathrm{~s}^{-1}\right)$ was necessary to draw the first bubbles into the downcomer. However, the gas holdup, $\varepsilon_{\mathrm{GD}}$, grew very fast at higher $U_{\mathrm{Gc}}$ values and quickly reached much higher values in comparison with all three-phase experiments. This difference originates from distinct cross-sectional area ratios, $A_{\mathrm{D}} / A_{\mathrm{R}}$ (see Table 1 ), which also accounts for the fact that the liquid velocity in the riser, $V_{\mathrm{LR}}$, is about four times higher than that in the downcomer, $V_{\mathrm{LD}}$, at the 3DT reactor set. Even at low air flow rates, the $V_{\mathrm{LR}}$ value is already high enough to push the majority of the bubbles coming from the riser through the lower part of the separator into the enlarged zone. At flow rates corresponding to $U_{\mathrm{Gc}}$ values higher than $0.03 \mathrm{~m} \mathrm{~s}^{-1}$, the influence of the lower separator part becomes dominant over the drifting force of the liquid coming from the riser section, resulting in the building-up of gas holdup in the downcomer. In the three-phase system, the downcomer gas holdup increases at much lower air flow rates. This happens probably because of the presence of the solid particles, which prevent the bubbles escaping from the lower part of separator. The solids slow down or stop the upward movement of the bubbles and force them to be entrained into the downcomer.

The magnitude of the influence of solids loading on $\varepsilon_{\mathrm{GD}}$ increased with the increase of the air flow rate for the ALR configuration with the dual separator (2DT and 3DT); whereas in the 1DT set, an approximately constant decrease of the downcomer gas holdup with an increase of the $U_{\mathrm{Gc}}$ value was observed (see Fig 2).

In the case of the reactor set $1 \mathrm{DT}$ (ALR with simple separator), the downcomer gas holdup was much lower (from two to three times) than in the case of the reactor with the dual separator (2DT and $3 \mathrm{DT}$ set, see Fig 3 ). For the 1DT set, the $\varepsilon_{\mathrm{GD}}$ curves increased with the increase of solids loading, reaching a maximum at the value of $14 \%$; for higher solids loading, the gas holdup decreased almost to the level of the gas-liquid dispersion. This surprising fact results from a distinct distribution of bubble sizes in the downcomer for this reactor set (1DT set). In comparison with the reactor set with dual separator (either 2DT or 3DT), where in a lower narrow part of the separator the substantial amount of bubbles of different sizes are dragged into the downcomer, only fine bubbles (with diameter of about $2-3 \mathrm{~mm}$ ) are entrained into the downcomer section at the 1DT set. There are no significant bubble coalescence events and the energy of circulation flow is high enough to recirculate most of them back to the riser. Thus, the residence time of bubbles is short, leading to very low downcomer gas holdups (see Figs 2(A) and 3). In

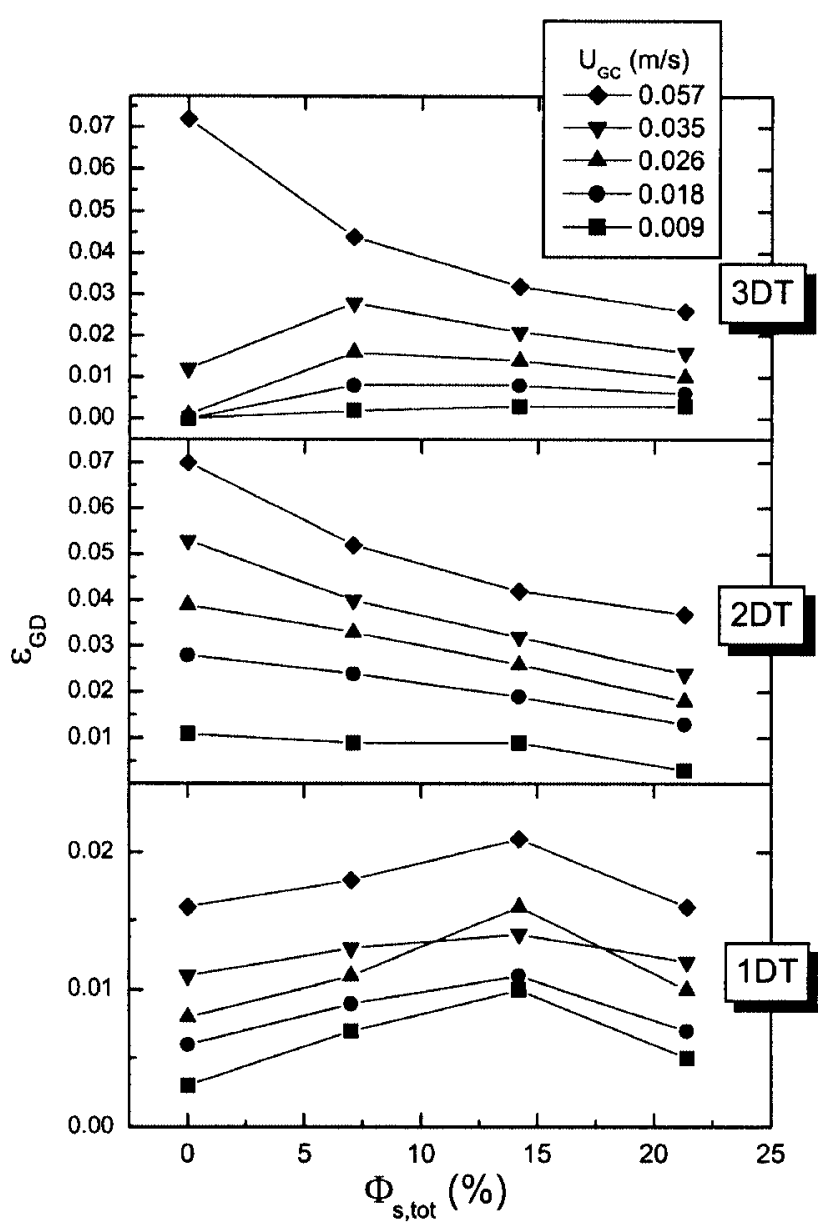

Figure 3. Gas holdup in downcomer versus solids loading $\phi_{\mathrm{S} \text {, tot }} . U_{\mathrm{Gc}}$ is the parameter for the individual lines. For explanation of reactor configurations 1DT, 2DT and 3DT, see Table 1. 
this situation, the presence of solids promotes bubble coalescence events and helps to keep them inside the downcomer. This mechanism works up to a certain limit of the solids loading $(14 \%(\mathrm{v} / \mathrm{v}))$, as at higher values the downcomer gas holdup started to decrease. In general, the higher the solids concentration, the smaller the volume to keep bubbles inside the section. At the highest solids loading $(21 \%(\mathrm{v} / \mathrm{v}))$, this effect became dominant and fewer bubbles were maintained in the downcomer.

The effect of the cross-sectional area ratio, $A_{\mathrm{D}} / A_{\mathrm{R}}$, and of the separator design on the riser gas holdup is depicted in Fig 2 . The highest $\varepsilon_{\mathrm{GR}}$ values were reached in the reactor configuration with the highest area ratio (3DT set). In fact, a decreasing area ratio leads to two opposite effects. On one hand, the superficial gas velocity in the riser tube increases at a constant gas flow rate yielding the increase of the riser gas holdup. On the other hand, the increase of the superficial liquid velocity decreases the bubble residence time and thus the gas holdup. In fact, comparing the 1DT and 2DT sets, the lower values of $\varepsilon_{\mathrm{GR}}$ found for the reactor with simple separator (1DT set) originate from the higher values of the liquid velocity due to the longer draft tube (see Fig 4).

The gas holdup was also determined in the separator zone, which represents a large portion of the total reactor volume. The gas holdup in the separator, $\varepsilon_{\mathrm{GS}}$, was found to be almost independent of the amount of solids (see Fig 2). This is due to a low concentration of particles in this section, even at the highest values of air flow rate. However, in the case of the 2DT and $3 \mathrm{DT}$ reactor sets (more significant in the $3 \mathrm{DT}$ set), a slight reduction in $\varepsilon_{\mathrm{GS}}$ was observed with the increase in solids loading. It could be observed that the bubbles rose up predominantly above the draft tube without being significantly dragged down on the walls of the separator. Thus, a large annular part of the separator is a bubble-free volume.

Finally, the total gas holdup in the reactor, $\varepsilon_{\mathrm{GTOT}}$, decreased with the increasing value of solids loading for all ALR configurations. The highest values of $\varepsilon_{\mathrm{GTOT}}$ were attained in the ALR configuration with a simple separator (1DT) in spite of very low values of downcomer gas holdup. This is due to the higher values of $\varepsilon_{\mathrm{GS}}$, which form the major contribution for the total gas holdup. Both reactor configurations with a dual separator (2DT and 3DT), independently from the variation in the cross-sectional area ratio, $A_{\mathrm{D}} / A_{\mathrm{R}}$, had approximately the same total gas holdup for the whole range of air flow rates tested.

\subsection{Liquid velocity}

The linear liquid velocity in the downcomer, $V_{\mathrm{LD}}$, increased with the increase of the air flow rates and the velocity curve showed an expected logarithmic shape. ${ }^{5}$ Further, the linear velocity was found to be independent of the solids loading, despite the expected increasing bubble coalescence events and friction losses that should result in a decrease of the velocity. Nevertheless, as the solids holdup increases with increasing solids loading in the main reactor sections, the free cross-sectional area for liquid flow decreases. The magnitude of the resulting true velocity will be thus dependent on which effect will be dominant-either the decrease of the free area for

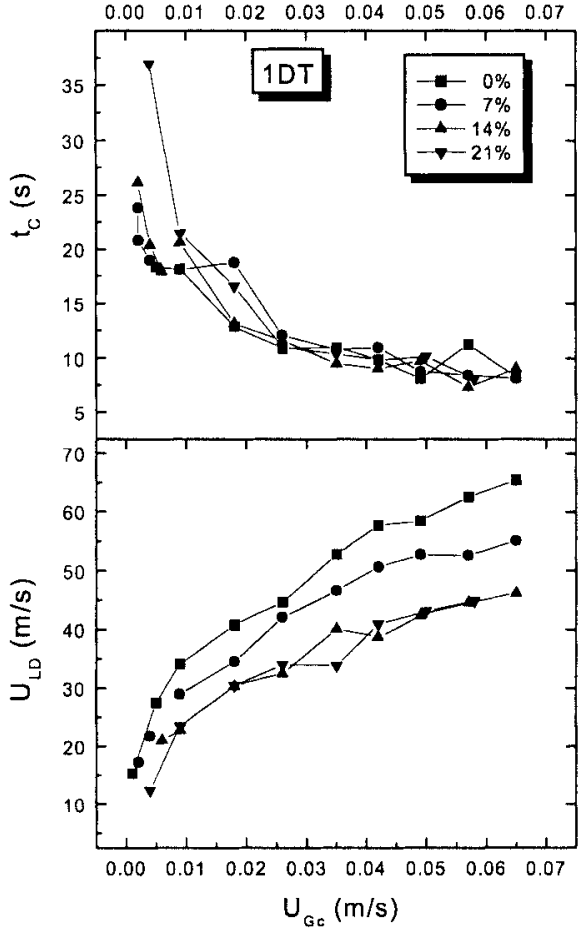

A.

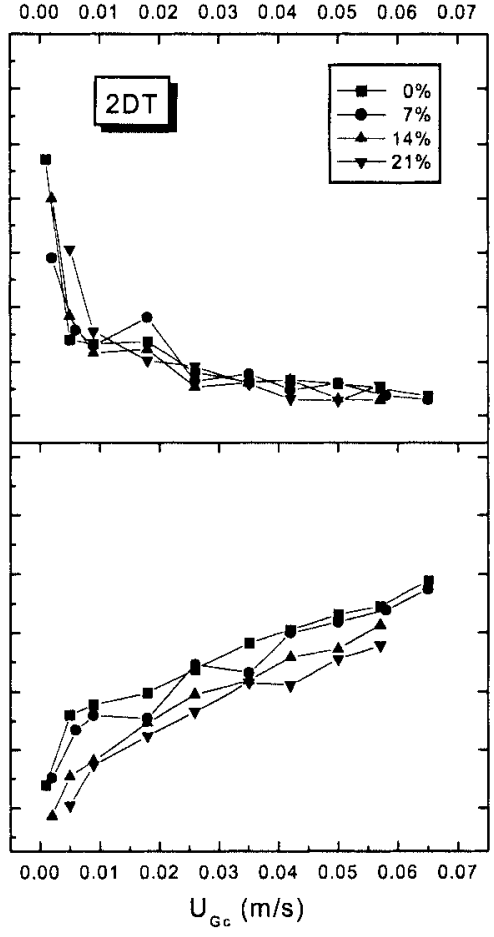

B.

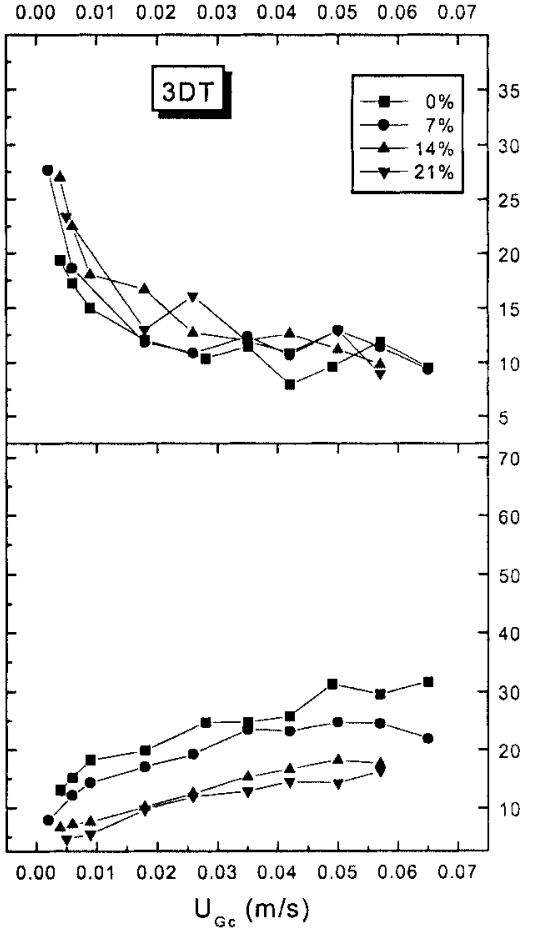

C.

Figure 4. Superficial liquid velocity in downcomer, $U_{\mathrm{LD}}$, and true circulation time, $t_{\mathrm{C}}$, versus air superficial velocity, $U_{\mathrm{Gc}}$, for different solids loadings: $0 \%, 7 \%, 14 \%$ and $21 \%(\mathrm{v} / \mathrm{v})$. A: ALR configuration 1DT, B: ALR configuration 2DT, C: ALR configuration 3DT (see also Table 1). 
liquid flux or the increase of friction loss and the decrease of the driving force. In order to find out how the liquid flux varies with solids loading, the superficial liquid velocity, $U_{\mathrm{LD}}$, was calculated as follows:

$$
U_{\mathrm{LD}}=V_{\mathrm{LD}}\left(1-\varepsilon_{\mathrm{GD}}-\varepsilon_{\mathrm{SD}}\right)
$$

Figure 4 shows the change of the superficial liquid velocity, $U_{\mathrm{LD}}$, and circulation time, $t_{\mathrm{C}}$, with the air flow rate and the solids loading for different ALR configurations. A decrease of the liquid flux with the solids loading could be observed in all cases. The curves of liquid velocity, $U_{\mathrm{LD}}$, for all reactor configurations exhibited a break point at lower air flow rates, where the slope of the curve suddenly decreased. The $U_{\mathrm{LD}}$ curve grew linearly with $U_{\mathrm{Gc}}$ up to this point, after which it displayed a slightly logarithmic shape. This point corresponds approximately to the two-phase circulation regime transition point-entrainment of bubbles into the downcomer appeared. ${ }^{22}$ The effect was more distinct in the ALR configuration with a dual separator (2DT and 3DT). Moreover, the break point was more evident in the system without solids and with low solids loading; at higher solids loadings the regime transition was damped and the onset of bubble penetration into the downcomer was more gradual.

Comparing the effect of reactor configurations 1DT and 2DT on liquid circulation (except the 3DT set with a much higher ratio of $A_{\mathrm{D}} / A_{\mathrm{R}}$ ), lower values of $U_{\mathrm{LD}}$ were reached in the reactor with a dual separator 2DT (by about 19\%). This is caused by a somewhat larger hydrostatic pressure difference between the riser and downcomer, ie the longer the draft tube, the higher the driving force. According to the work of Chisti, ${ }^{23}$ the liquid velocity is proportional to the square root of the height of the draft tube $H_{\mathrm{D}}{ }^{0.5}$. In the present case, the shortening of the draft tube from 1.4 to $1.2 \mathrm{~m}$ should result in the decrease of $V_{\mathrm{L}}$ by only $7 \%$. However, the reduction of the draft tube also changed the separator design (see Fig 1), resulting in an increase of $\varepsilon_{\mathrm{GD}}$ and consequently a decrease of the driving force. Hence, a decrease of the liquid velocity was observed to be higher than expected.

\subsection{Circulation time}

As shown in Figs 4 and 5, the overall circulation time, $t_{\mathrm{C}}$, decreased with increasing air flow rate. The effect was more evident at low values of $U_{\mathrm{Gc}}$, whereas at high values of $U_{\mathrm{Gc}}$ only a slight decline of $t_{\mathrm{C}}$ was observed. This means that the improvement of the liquid circulation by means of an increase of the air flow rate strongly decreases for higher values of $U_{\mathrm{Gc}}$. In contrast, the effect of the solids loading on the circulation time was negligible (see Fig 4) - no evident decrease of $t_{\mathrm{C}}$ could be observed with the increase of solids concentration in the reactor. Since the linear liquid velocities in the riser, $V_{\mathrm{LR}}$, and downcomer, $V_{\mathrm{LD}}$, were independent of the solids loading, it can also be concluded that the true liquid residence time

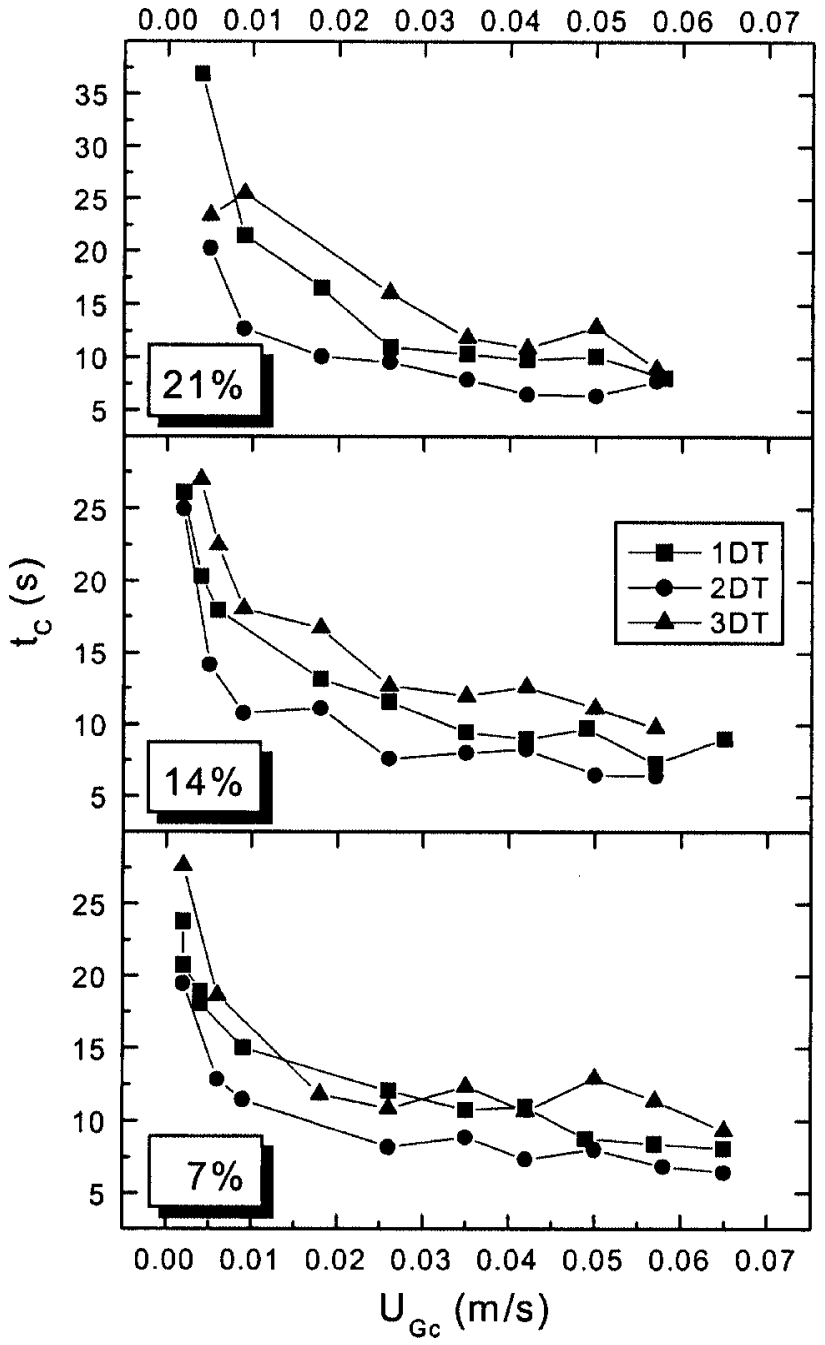

Figure 5. Overall circulation time $t_{\mathrm{C}}$, versus the superficial gas velocity, $U_{\mathrm{Gc}}$, for different reactor configurations 1DT, 2DT and 3DT (see Table 1) and for different solids loadings: $7 \%, 14 \%$ and $21 \%(v / v)$.

in the separator is not affected by changes of the solids concentration in the reactor.

Variations in $t_{C}$ were observed with the change of the ALR configuration (see Fig 5). It is evident that for the evaluation of the influence of ALR configurations with different cross-sectional area ratios on the overall fluid circulation, the values of the circulation time, $t_{\mathrm{C}}$, have to be used instead of the velocities in the riser and the downcomer. It can be seen that the reduction of the diameter of the draft tube $(2 \mathrm{DT} \rightarrow 3 \mathrm{DT})$ reduced the overall fluid circulation. This is due to the fact that the increase of friction losses around the circulation loop at the bottom and top because of the flow contraction/expansion became dominant over the increasing driving force caused not only by the reduction of the bubble penetration into the downcomer, but also by the increase of the riser gas holdup (see Fig 2).

It can be concluded that the presence of the dual separator and the equality of cross-sectional areas of riser and downcomer enhances the total fluid circulation. While the flow in riser and downcomer 
sections mainly contributes to the total fluid flow at the ALR with a dual separator (for the shorter draft tube-2DT and 3DT), the overall circulation is significantly affected by fluid flowing in the enlarged separator zone at the ALR with a simple separator zone (1DT set). Moreover, the increase of the ratio of $A_{\mathrm{D}} / A_{\mathrm{R}}$ in the 3DT set slows down the overall circulation and that was dominant over the effect of a slower liquid flow in the separator zone at the 1DT reactor set (see Fig 5). For all that, the highest values of the circulation time occurred in the ALR with a simple enlarged separator and/or at the highest ratio of $A_{\mathrm{D}} / A_{\mathrm{R}}$.

\subsection{Solids distribution in the ALR}

\subsubsection{Effect of solids loading and gas flow rate}

The change of the solids holdup in all sections of the ALR with the solids loading and air flow rate is shown in Fig 6. For all ALR configurations investigated, the solids holdup in the riser, $\varepsilon_{\mathrm{SR}}$, decreased with the increase of the air flow rate. This decline was more pronounced with the increase of the solids loading. At the highest air flow rates, steady values of $\varepsilon_{\mathrm{SR}}$ were attained for all solids loading except for the highest one $(21 \%)$. As was expected, $\varepsilon_{\mathrm{SR}}$ increased with the increasing solids loading. The solids holdup in the downcomer $\left(\varepsilon_{\mathrm{SD}}\right)$ exhibited a similar dependence on the air flow rate and solids loading, showing however lower values than those obtained in the riser. Nevertheless, one exception was observed in the configuration with the simple separator 1DT - the $\varepsilon_{\mathrm{SD}}$ and $\varepsilon_{\mathrm{SR}}$ holdups were very similar for the two highest solids loadings ( 14 and $21 \%$ ). It indicates that the increased amount of solids inside the reactor was distributed solely into the separator zone. In contrast, the value of solids holdup in the separator zone $\varepsilon_{\text {SS }}$ increased gradually with the increase of air flow rate.

\subsubsection{Solids distribution in sections of three-phase airlift reactor}

The distribution of solids in the riser, downcomer and separator sections of ALR at different values of solids loading is shown in Fig 7. The solids holdup in both main vertical sections of the ALR, $\varepsilon_{\mathrm{SR}}$ and $\varepsilon_{\mathrm{SD}}$, decreased with increasing air flow rate, converging to a constant value at the highest values of $U_{\mathrm{Gc}}$. It means that a uniform distribution in the reactor (except the enlarged head zone) was achieved for the highest values of the air flow rate. This assumption is often used in works dealing with the experimental investigation and hydrodynamic modelling of threephase flow in ALR (eg Lu et $a l^{21}$ ). In the present case, a homogeneous distribution of the solid phase was attained at both reactor configurations with a wide inner tube (1DT and 2DT sets); however, there are some disturbances on the solids holdup curves, making quantification of general conclusions difficult (eg an increase of difference between $\varepsilon_{\mathrm{SR}}$ and $\varepsilon_{\mathrm{SD}}$ for the highest values of the air flow rate in the $1 \mathrm{DT}$ set). It was difficult to determine accurately the critical values of gas flow rate and solids concentration, which would ensure uniform solids distribution between riser and downcomer sections. However, it can be said that the non-uniformity of solids distribution between riser and downcomer generally increased with the increase of solids loading and the decrease of gas flow rate.

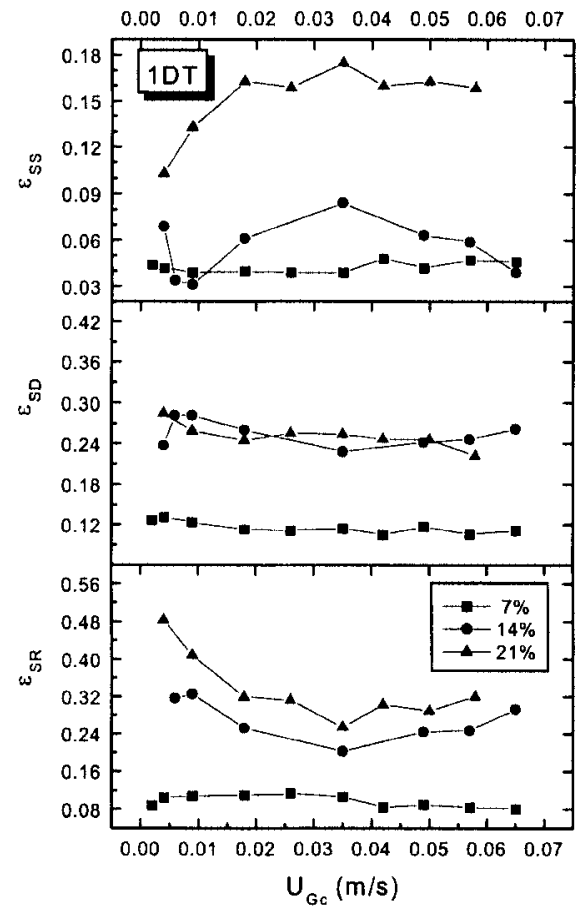

A.

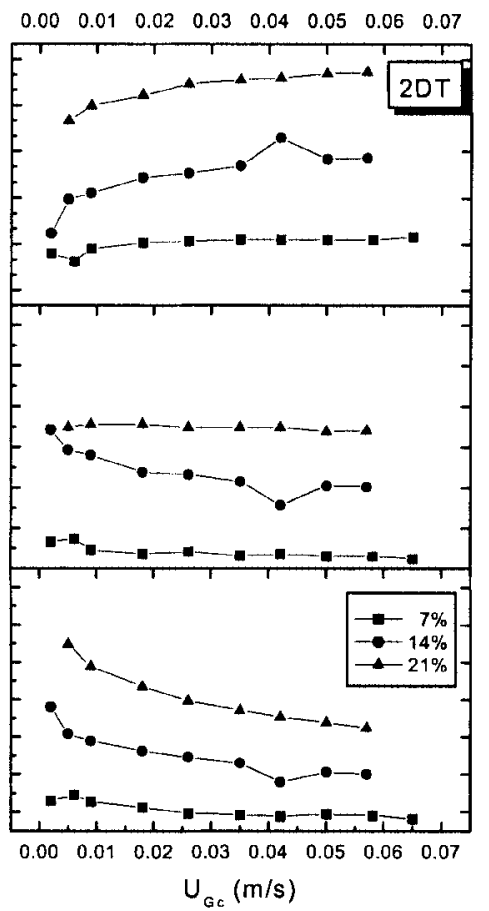

B.

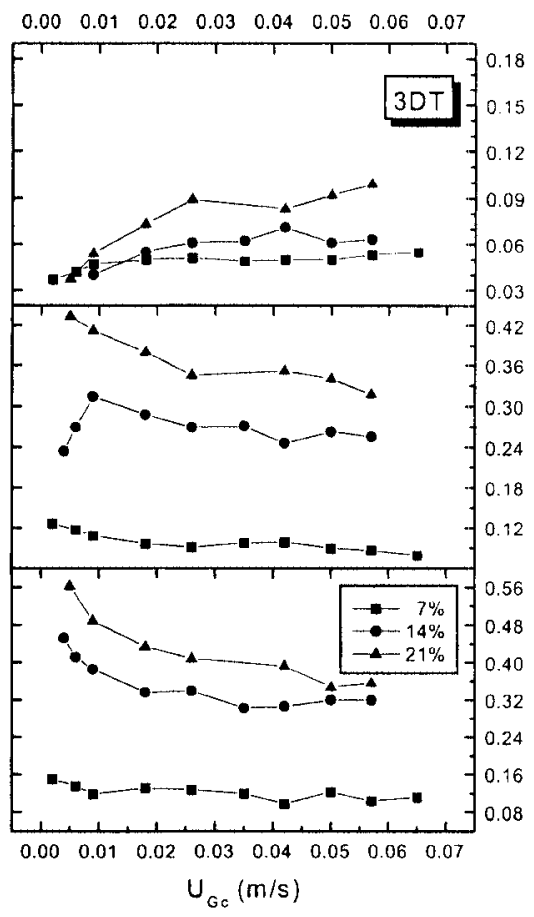

C.

Figure 6. Solids holdup in individual sections of the ALR versus air superficial velocity, $U_{\mathrm{Gc}}$, for different solids loadings: $0 \%, 7 \%, 14 \%$ and $21 \%$ (v/v). A: ALR configuration 1DT, B: ALR configuration 2DT, C: ALR configuration 3DT (see also Table 1). 


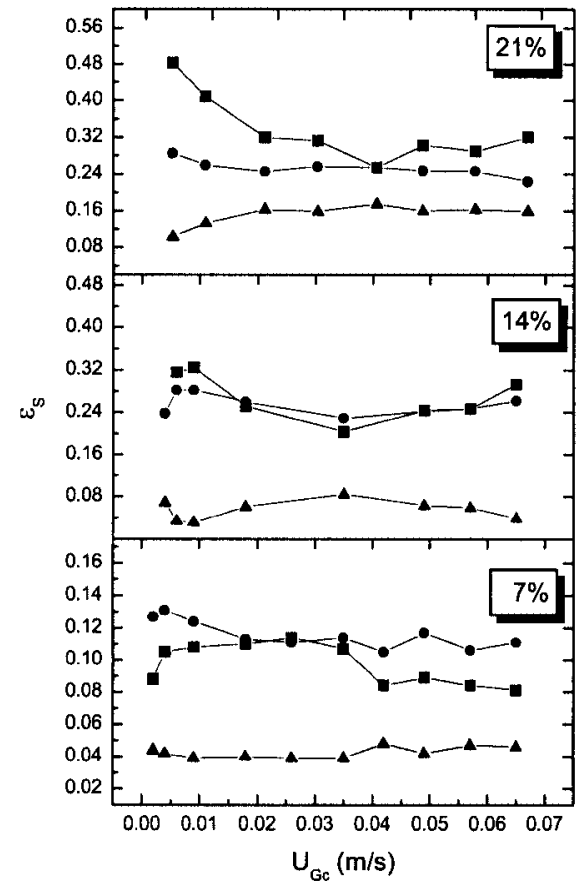

A.

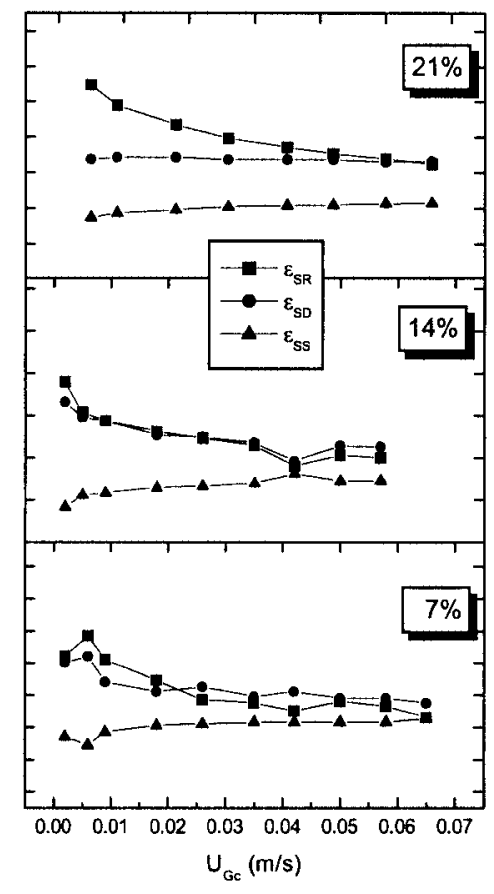

B.

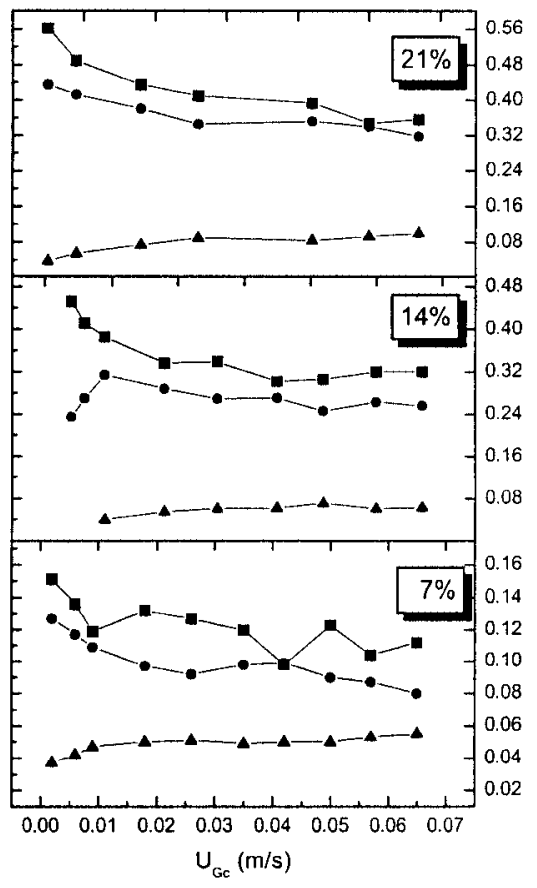

C.

Figure 7. Solids distribution in riser, downcomer and separator sections of the ALR as a function of the air superficial velocity, $U_{\mathrm{Gc}}$, for different solids loadings: $0 \%, 7 \%, 14 \%$ and $21 \%(v / v)$. A: ALR configuration 1DT, B: ALR configuration 2DT, C: ALR configuration 3DT (see also Table 1).

Nevertheless, it is clearly seen that the most uniform solids distribution was achieved in the $2 \mathrm{DT}$ reactor set, for which eventually a homogeneous distribution of the solid phase in the whole range of the gas flow rates applied could be found at low values of solids loading. At the solids loading of $21 \%$, this equality was attained only at gas velocities, $U_{\mathrm{Gc}}$, as high as $0.05 \mathrm{~m} \mathrm{~s}^{-1}$. The most uneven solids distribution was found in the $3 \mathrm{DT}$ reactor set despite the fact that a much lower minimum (or critical) air flow rate, $U_{\mathrm{Gcrit}}$, was needed to get solids suspension in the whole column (see Table 2). On the other hand, the separator design did not have any influence on $U_{\mathrm{Gcrit}}$.

For all cases studied, the solids holdup in the separator, $\varepsilon_{S S}$, was found to be markedly lower than that in the riser and downcomer sections. It confirms an efficient sedimentation of solid particles in that zone. Since the enlarged settling zone represents a large portion of the total reactor volume (from 50 to $63 \%$ ), the volume of solids located in this zone represents a very large portion of the total amount of solids in the reactor. The percentage ratio of solids volume in the separator to the total volume of solids ranged from 19 to $54 \%$. This

Table 2. Minimum (or critical) air flow rate, $U_{\text {Gcrit }}$ (in $\mathrm{ms}^{-1}$ ), for achieving solids suspension in the whole column

\begin{tabular}{lccc}
\hline & \multicolumn{3}{c}{ Solids loading } \\
\cline { 2 - 4 } Draft tube(DT) & $7 \%(\mathrm{v} / \mathrm{v})$ & $14 \%(\mathrm{v} / \mathrm{v})$ & $21 \%(\mathrm{v} / \mathrm{v})$ \\
\hline 1DT & 0.004 & 0.006 & 0.026 \\
2DT & 0.004 & 0.006 & 0.026 \\
3DT & 0.002 & 0.004 & 0.006 \\
\hline
\end{tabular}

means that any change of the reactor design or of its operation, even if resulting in a slight increase in the solids holdup in the separator, may provoke a significant alteration of the solids distribution in the whole reactor.

\section{CONCLUSIONS}

The present study showed that the measuring techniques proposed for the characterization of hydrodynamics permitted the acquisition of important information on multiphase flow and distribution of gas and solid phases in the ALR. Similar solids distribution in the riser and downcomer were found in all reactor configurations studied. Nevertheless, uniform distribution was achieved only at higher gas flow rates, particularly when the reactor operated with the highest solids loading $(21 \%(\mathrm{v} / \mathrm{v}))$. The measurements revealed very low solids holdup in the enlarged separator zone and its low sensitivity to changes of the air flow rate. However, owing to the large volume of the separator zone, any change of the reactor design or of its operation leading to an even slight increase of the solids holdup will cause significant accumulation of solids in the separator.

It was demonstrated that the separator design affects the gas holdup as well as the bubble size distribution in the downcomer via its influence on liquid velocity. Much smaller bubbles were located in the downcomer in the case of the ALR with a simple enlarged separator (1DT set) when compared with the ALR with a dual separator (2DT and 3DT sets), resulting in significantly different hydrodynamic behavior of the reactor. 
A cross-sectional area of the downcomer greater than that of the riser (ratio $A_{\mathrm{D}} / A_{\mathrm{R}}$ ranging from 1.2 to 2.0) should be used to accomplish an even distribution of solid phase in all reactor sections. A very high ratio $\left(A_{\mathrm{D}} / A_{\mathrm{R}}\right)$ leads to the deceleration of the overall circulation and to the decrease of solids holdup in the enlarged separator zone, giving rise to non-uniformities of the solids distribution in the whole reactor. It forms a less gentle hydrodynamic environment, which may be a crucial disadvantage for applications in bioprocesses using particles that are sensitive to shear.

It was finally proposed to use the internal-loop ALR with a dual separator and the $A_{\mathrm{D}} / A_{\mathrm{R}}$ ratio between 1.2 and 2.0 for batch/continuous high cell density systems, where the uniform distribution of solid phase, its efficient separation of particles from the liquid phase, and an improved residence time of air bubbles inside the reactor are desirable. Besides that, the lower part of the dual separator acts as an efficient mixer, which helps to improve the overall mixing in the ALR.

The results of this study can be applied to suggest optimal hydrodynamic conditions in batch/continuous TPAL bioreactors for high cell density fermentations, such as those using immobilized or flocculating biosystems.

\section{ACKNOWLEDGEMENT}

This research has been supported by a Marie Curie Fellowship of the European Community programme 'Improving Human Research Potential' under contract number HPMF-CT-2002-01643.

\section{REFERENCES}

1 Moo-Young M (ed), Bioreactor Immobilized Enzymes and Cells-Fundamentals and Applications. Elsevier Applied Science Publishers, London and New York, p 327 (1988).

2 van Benthum WAJ, Integrated nitrification and denitrification in biofilm airlift reactors: biofilm development, process design and hydrodynamics. PhD Thesis, Delft University of Technology, Delft, The Netherlands (1998).

3 Domingues L, Dantas MM, Lima N and Teixeira JA, Continuous ethanol fermentation of lactose by a recombinant flocculating Saccharomyces cerevisiae strain. Biotechnol Bioeng 64(6):692-697 (1999)

4 Heck J and Onken U, Characteristics of solid suspensions in a bubble column without and with draft tube. Chem Eng Technol 11:335-341 (1988).

5 Chisti Y, Airlift Bioreactors. Elsevier Science Publishers, London (1989).

6 Weiland P, Influence of draft tube diameter on operation behaviour of airlift loop reactors. Germ Chem Eng 7:374-385 (1984).
7 Miyahara T, Hamaguchi M, Sukeda Y and Takahashi T, Size of bubbles and liquid circulation in a bubble column with a draught tube and sieve plate. Can $\mathcal{f}$ Chem Eng 64(October):718-725 (1986).

8 Vicente AA and Teixeira JA, Hydrodynamic performance of a three-phase airlift bioreactor with an enlarged degassing zone. Bioproc Eng 14:17-22 (1995).

9 Gavrilescu M and Tudose RZ, Effects of downcomer-to-riser cross sectional area ratio on operation behaviour of externalloop airlift bioreactors. Bioproc Eng 15:77-85 (1996).

10 Al-Masry WA and Abaseed AE, On the scale-up of external lop airlift reactors: Newtonian systems. Chem Eng Sci 53(24):4085-4094 (1998).

11 Siegel MH, Merchuk JC and Schugerl K, Air-lift reactor analysis: interrelationships between riser, downcomer, and gas-liquid separator behavior, including gas recirculation effects. AlChE F 32(10):1585-1596 (1986).

12 Merchuk JC, Ladwa N, Cameron A, Bulmer M and Pickett A, Concentric-tube airlift reactors: effects of geometrical design on performance. AIChE $\mathcal{F}$ 40(7):1105-1117 (1994).

13 Choi KH, Chisti Y and Moo-Young M, Influence of the gas-liquid separator design on hydrodynamic and masstransfer performance of split-channel airlift reactors. $\mathcal{f}$ Chem Technol Biotechnol 62(4):327-332 (1995).

14 Moresi M, Optimal design of airlift fermenters. Biotechnol Bioeng XXIII:2537-2560 (1981).

15 Siegel MH and Merchuk JC, Hydrodynamics in rectangular airlift reactors: scale-up and the influence of gas-liquid separator design. Can f Chem Eng 69(April):465-473 (1991).

16 Klein J, Godó Š, Dolgoš O and Markoš J, Effect of gas-liquid separator on the hydrodynamics and circulation flow regimes in internal-loop airlift reactors. $\mathcal{f}$ Chem Technol Biotechnol 76(5):516-524 (2001).

17 Freitas C and Teixeira JA, Hydrodynamic studies in an airlift reactor with an enlarged degassing zone. Bioproc Eng 18:267-279 (1998).

18 Klein J, Blažej M, Godó Š, Dolgoš O and Markoš J, Application of a magnetic tracer method for the characterisation of hydrodynamics in internal-loop airlift bioreactors. Chem Papers 54(6b):456-466 (2000).

19 Wenge F, Chisti Y and Moo-Young M, A new method for the measurement of solids holdup in gas-liquid-solid three-phase systems. Ind Eng Chem Res 34:928-935 (1995).

20 Verlaan $\mathrm{P}$ and Tramper J, Hydrodynamics, axial dispersion and gas-liquid oxygen transfer in an airlift-loop bioreactor with three-phase flow, in International Conference of Bioreactors and Biotransformations. Gleneagles, Scotland, UK, pp 363-373 (1987).

21 Lu WJ, Hwang SJ and Chang CM, Liquid velocity and gas holdup in 3-phase internal loop airlift reactors with low-density particles. Chem Eng Sci 50(8):1301-1310 (1995).

22 Heijnen JJ, Hols J, van der Lans RJGM, van Leeuwen HLJM, Mulder A and Weltevrede R, A simple hydrodynamic model for the liquid circulation velocity in a full-scale twoand three-phase internal airlift reactor operating in the gas recirculation regime. Chem Eng Sci 52(15):2527-2540 (1997).

23 Chisti Y and Moo-Young M, Prediction of liquid circulation velocity in airlift reactors with biological media. $f$ Chem Technol Biotechnol 42:211-219 (1988). 